\title{
When not to swim against the tide
}

Governments are habitually seeking to regulate the distribution of electromagnetic signals within and even outside their territory, but usually for reasons more concerned with wish-fulfilment than technological logic.

FIRST of all, a parable corrected: the King of England called Canute (995-1035) did not (repeat $n o t$ ) take up a position on the coast of southern England below the high-water mark so as to demonstrate to his people that he could keep the incoming tide at bay, but on the contrary to show them that even one as much revered as he could not influence natural phenomena. It would be a great help to us all if modern governments could follow Canute's modest example, especially in the exercise of their perennial ambition to mould technology to their wishes. So much should now be clear, in the United States and Western Europe, from the way in which tidy-minded arrangements for shaping the development of the telecommunications and television industries are everywhere collapsing because of developments that governments and their regulators failed to foresee.

Take, for example, the United States. Once upon a time, there was a telephone company called the Bell System (or, by those with fond feelings towards it, "Ma Bell") which had equipped itself to connect most telephone users in the United States to others like themselves and those living overseas as well. Because it had become a de facto monopoly, state and federal governments took powers to regulate the prices it charged for its services, but nobody was content with that. So the time came when the Bell System was broken up by the federal courts into several component parts: a handful of regional telephone companies (called "baby Bells") and an international carrier called AT\&T, which naturally was constrained from competing by means of copper wires with the regional companies. What the courts could not have known was that cellular telephones based on radiotelephony would become feasible and fashionable, and that AT\&T would buy (last month) a successful cellular telephone company called McCaw and be well placed to service a substantial fraction of the more profitable customers for telephone service in the United States.

A different kind of nonsense has been perpetrated in Britain, where the once-nationalized telephone monopoly has been turned into a private company owned by shareholders, many of them ordinary people. Instead of the US formula of disaggregation, the British government has chosen to regulate the de facto monopoly that stems from British Telecom's ownership of copper wire threaded to most British houses by direct regulation of its tariffs, by requiring that it should make its network accessible to competitors and by restricting its freedom, at least for the time being, to provide cable television to potential customers. Now, a full decade after Mr Kenneth Baker, then a member of the British government, was promising "to cable" Britain in the succeeding ten minutes or so, the cable companies are cheerfully chipping away at British Telecom's telephone business.

In Western Europe as a whole, there is a greater muddle. Most telephone companies remain nationalized industries (and some, such as the German, are grossly inefficient). The distribution of encrypted television signals from satellites is growing quickly, as is cable television and cellular telephony. Governments have adopted a variety of regulations ranging from tight control to wishful thinking. Television broadcasts raise most hackles. Some governments regard foreign broadcasts as an assault on national culture, which conflicts with the European Commission's directive requiring the free flow of television signals within Europe. And that has the consequence that the British government, which has set its face against pornography on television, cannot regulate such signals spilling over from elsewhere if nobody requires that they should be paid for.

These are only some of the symptoms of the contradictions of principle still being built into national and international systems for regulating the distribution of electromagnetic signals of various kinds. Of course, it is entirely proper that commercial organizations should not be allowed to hold countries or international groupings to ransom by exploiting de facto monopolies established by the sheer volume of their present business, but what the sorry record of the past few decades has shown is that, at least in telecommunications, structural regulation is likely to be less effective than financial regulation. And even that may be less necessary than commonly supposed, given the apparently endless lode of technical innovation now being worked. That, of course, is the point that Canute was trying to make.

\section{Europe's nomenclature}

The Maastricht Treaty has sown confusion in the names of European institutions.

THE celebration last weekend by Europe's political leaders of the entry into force of the Maastricht Treaty was properly modest. Winning ratification of the treaty has been a burden for most of them. It may even turn out to have been an albatross around some necks, a sign of electoral trouble 